\title{
Representação social de pacientes em situação de hospitalização sobre a unidade de terapia intensiva
}

\section{Social representation of hospitalized patients on the intensive care unit}

\author{
Eriedna Chaves Soares' $\bullet$ Juliana Xavier Pinheiro da Cunha ${ }^{2}$ Chrisne Santana Biondo ${ }^{3}$ \\ Anna Karina Lomanto Rocha ${ }^{4}$
}

\begin{abstract}
RESUMO
Essa pesquisa teve como objetivo conhecer e analisar as representações sociais sobre UTI construídas por pacientes que vivenciaram a hospitalização nesta unidade. Trata-se de um estudo de campo, descritivo e exploratório com abordagem qualitativa embasado pela Teoria das Representações Sociais, realizado em um hospital público, situado na região do sudoeste da Bahia, a coleta de dados ocorreu nas clínicas médica e cirúrgica com I5 pacientes após a alta da UTI adulto. A coleta envolveu entrevista semiestruturada, os dados foram apreciados mediante análise de conteúdo de Bardin. O resultado abarcou as três seguintes categorias: ( I) Aspectos envolvidos na mudança da percepção sobre a UTI; (2) Ambiente gerador de desconfortos e sofrimentos; e (3) Mecanismos de enfrentamento para período de internação. Verificou-se que o ambiente da UTI anterior a internação é pautada nas definições do senso comum, a transformando em um espaço gerador de medo, morte, tristeza e sofrimento biopsicossocial. Contudo, após a vivencia da internação na unidade, mudanças positivas ocorreram na representação da UTI, atribuindo-a como local seguro, de recuperação e reestabelecimento da saúde, além de ser acolhedor pelos profissionais empáticos e humanos. A pesquisa constatou a mudança de percepção associada a UTI, embora tenha evidenciado vários aspectos negativos, como o distanciamento familiar, os pacientes demonstraram situações que influenciaram positivamente, sendo determinantes para modificação do pensamento socialmente elaborado.
\end{abstract}

Palavras-chave: Unidades de Terapia Intensiva; Hospitalização; Percepção.

\begin{abstract}
This research aimed to know and analyze the social representations about ICU built by patients who experienced hospitalization in this unit. This is a descriptive and exploratory field study with a qualitative approach based on the Theory of Social Representations, carried out in a public hospital, located in the southwest region of Bahia. Data collection occurred at the medical and surgical clinics with 15 patients after the discharge from the adult ICU.The collection involved a semi-structured interview, the data were analyzed through Bardin content analysis. The result embraced the following three categories: (I) Aspects involved in changing the perception about the ICU; (2) Environment that generates discomfort and suffering; and (3) Coping mechanisms for hospitalization period. It was found that the ICU environment prior to hospitalization is based on common sense definitions, transforming it into a space that generates fear, death, sadness and biopsychosocial suffering. However, after the experience of hospitalization in the unit, positive changes occurred in the representation of the ICU, assigning it as a safe place, recovery and reestablishment of health, in addition to be welcoming by empathic and human professionals. The research found the change in perception associated with the ICU, although it showed several negative aspects, such as family distancing, patients showed situations that influenced positively, being determinant for modification of socially elaborated thinking.
\end{abstract}

Keywords: Intensive Care Units; Hospitalization; Perception.

I Enfermeira, graduada pela Universidade Federal da Bahia - UFBA, Campus Anísio Teixeira. Enfermeira coordenadora da Atenção Básica da Secretaria Municipal de Aracatu.

2 Enfermeira, doutorando em epidemiologia pela Universidade Federal do Rio Grande do Sul-UFRGS. Professora assistente da Universidade Federal da Bahia- UFBA. 3 Enfermeira, doutorando em ciências da saúde pela Universidade Estadual do Sudoeste da Bahia-UESB. Professora assistente da Universidade Federal da Bahia-UFBA.

4 Enfermeira, mestre em Enfermagem Universidade Federal da Bahia- UFBA. Residência em terapia intensiva pela escola de Enfermagem da UFBA. Coordenadora de Enfermagem da Unidade de Terapia Intensiva adulto do Hospital Geral deVitória da Conquista- HGVC. 


\section{INTRODUÇÃO}

A Unidade de Terapia Intensiva (UTI) é um ambiente que tem por objetivo prestar assistência a pacientes que possuem alguma condição clínica grave, necessitando de cuidados ininterruptos e contínuos. Esse suporte intensivo facilita a manutenção da vida através da utilização de um aparato tecnológico e farmacológico específico e complexo, além de uma equipe multiprofissional com conhecimentos ampliados de fisiologia e anatomia humana ${ }^{(1)}$.

A predominância de tecnologias duras, recursos materiais e humanos altamente especializados, fazem da UTI um ambiente que potencializa uma assistência mecanizada, onde o foco principal é o biológico. Isso favorece a ocorrência de estresse para os pacientes e seus familiares, que relatam sentimentos como angústia, medo da morte e sofrimento ${ }^{(2)}$. Essa percepção compartilhada socialmente torna a UTI um ambiente estigmatizante, marcado por aspectos negativos relacionados a internação.

Os fatores ambientais também são estressores que caracterizam a UTI como um lugar frio e sem conforto, devido a iluminação contínua, a atemporalidade (dificuldade em se situar no tempo), além da disposição dos pacientes em decúbito dorsal na maior parte da interação, gerando muitas dores e desconfortos. Esses aspectos além de não favorecerem o bem-estar e a recuperação dos pacientes, reforçam todos os conceitos negativos, socialmente elaborados sobre esta unidade ${ }^{(3)}$.

Entretanto, mesmo havendo melhorias na ambiência da UTI, o distanciamento familiar e as mudanças do padrão de vida também suscitam experiências desagradáveis relacionadas à hospitalização. A separação da família, e os poucos e rápidos momentos de visita, provocam sentimentos de isolamento social e representam barreiras para o melhor relacionamento paciente/família/equipe ${ }^{(2)}$.

No entanto, quando a equipe multiprofissional desenvolve uma comunicação efetiva, respeitando a espiritualidade do paciente e as suas individualidades, contribui para aliviar essas percepções negativas. Nesse sentido, a humanização no cuidado, constitui-se um elo para se promover uma atenção individualizada, ao estimular a empatia, a fim de garantir práticas em saúde que transcenda as dimensões orgânico-funcionais do ser humano(4).

Nesse contexto, é necessário que o profissional compreenda todas as concepções socialmente formadas que cercam o cuidado na UTI para o paciente.Assim, a Teoria das Representações Sociais (TRS) contribui para investigar essas percepções construídas, pois, segundo Eulálio ${ }^{(3)}$, este ambiente carrega um conjunto de conceitos, denominações e significados culturais negativos, construídos pelo senso comum, em associação às experiências e formações de saberes individuais e coletivos.

As Representações sociais são vistas como fenômenos construídos no cotidiano, para tornar familiar o não familiar. ATRS busca a compreensão da construção e do uso do conhecimento na vida real cotidiana, e faz com que o objeto seja reconhecido e compreendido a partir de uma experiência anterior. Esta representação comporta "uma dimensão cognitiva na medida em que ela favorece uma experimentação do mundo e sobre o mundo e contribui para a construção de realidades segundo categorias ou formas socialmente dadas"(5).

Desta forma, frente a importância de se identificar os universos consensuais sobre os conceitos socialmente elaborados a respeito da UTI e da influência dessas representações no processo de internação, em consonância aos poucos artigos encontrados que abordem a temática a luz da TRS, pretende-se com esta pesquisa responder a seguinte pergunta: Quais as representações que $\circ$ paciente atribui à UTI após vivenciar o internamento nesse setor? Com base nessa questão norteadora, foi formulado o seguinte objetivo: conhecer e analisar as representações sociais de pacientes sobre a internação em UTI construídas após vivenciarem a hospitalização nesta unidade.

\section{METODOLOGIA}

Estudo de campo, descritivo e exploratório com abordagem qualitativa embasado pela TRS, realizado em um hospital público, de referência local, situado na região do sudoeste da Bahia, a coleta de dados ocorreu nas clínicas médica e cirúrgica após a alta dos indivíduos da UTI adulto.

A seleção dos participantes obedeceu aos critérios não probabilísticos, por conveniência, realizada aleatoriamente através da escolha de indivíduos acessíveis, que permitiram contato direto e imediato nos setores de internamento do referido cenário, com nível de consciência preservado, verificado pela aplicação da escala de Full Outline of UnResponsiveness (FOUR) com score 16, idade igual ou superior a 18 anos, que vivenciaram internação em UTI por pelo menos 48 horas, critério que visou garantir um tempo mínimo e razoável para que o sujeito obtivesse percepções acerca do serviço. Assim, foram entrevistados 15 participantes, delimitados pelo critério de saturação dos dados.

A coleta de dados foi realizada no período de abril de 2019 mediante entrevista semiestruturada com as seguintes questões: $O$ que a UTI representa para você? I Como você descreve a sua experiência na UTI? / Como você se sentiu quando esteve internado na UTI? / Você identifica alguma mudança na visão que tem hoje a respeito da UTI daquela que possuía antes do internamento? Se sim, qual (is) e o que te fez mudar de visão? / Caso existam, quais os aspectos positivos e/ou negativos relacionados à UTI que você identifica?

A coleta foi realizada junto ao leito durante o internamento nos setores médico e cirúrgico, após alta da UTI. As respostas foram gravadas em aparelho de áudio 
mediante autorização dos participantes, após apresentação do objetivo da pesquisa, os áudios tiveram duração de 7 a 18 minutos, foram transcritos e analisados a fim de estruturar os dados para serem apreciados mediante a análise de conteúdo de $\operatorname{Bardin}^{(6)}$, na qual estabelece uma lógica entre as comunicações, pela diversidade e diferenças da conversação e do diálogo, essa abordagem contribui com o pesquisador ao proporcionar deduções lógicas e justificativas frente a transcrição dos dados obtidos nas palavras dos sujeitos entrevistados, para posterior categorização e elucidação dos agrupamentos que emergiram com enfoque na literatura ${ }^{(6)}$.

Como garantia de anonimato dos participantes, foram utilizados nomes fictícios de pedras preciosas para identificá-los. Foram respeitadas as exigências contidas na Resolução $\mathrm{N}^{\circ} 466$ de $2012^{(7)}$, referente a proteção em pesquisa científica no qual envolvem seres humanos, em cumprimento à sua autonomia e liberdade. $O$ projeto de pesquisa foi aprovado pelo Comitê de Ética e Pesquisa da Universidade Federal da Bahia (CEP-UFBA), em 0I/04/2019, CAAE: 046224I8.7.0000.5556.

\section{RESULTADOS}

A análise dos dados resultou nas três seguintes categorias: (I) Aspectos envolvidos na mudança da percepção sobre a UTI; (2) Ambiente gerador de desconfortos e sofrimentos; e (3) Mecanismos de enfrentamento para período de internação.

\section{Aspectos envolvidos nos estigmas e mudança da percepção sobre a UTI}

$\mathrm{Na}$ primeira categoria foi evidenciado, a partir das falas dos participantes, os estigmas socialmente elaborados sobre a UTI. Eles descreveram a percepção que possuíam do ambiente e do público atendido neste setor, antes de vivenciarem o processo de internação, prevalecendo a associação com o fim da vida, medo, morte e tristeza.

Eu achava que quem ia pra UTI não voltava mais [..] já ia morrendo, uma pessoa consciente pra mim não ia pra UTI, tinha que estar morrendo mesmo. (Âmbar)

A UTI representava um lugar muito triste, o paciente que vai para UTI só está esperando a hora de morrer. (Opala)

Percebe-se que a internação em uma UTI gera na sociedade inúmeras incertezas e preocupações, por ser um ambiente desconhecido que provoca medos, principalmente pela associação com a gravidade clínica dos pacientes internados, conforme evidenciado na fala da participante.

Agora de manhã meu esposo me disse que os vizinhos estavam perguntando se eu tinha morrido, porque sabia que eu tinha ido para UTI. (Esmeralda)

Contudo, tornou-se evidente nos relatos que os pacientes, após passarem pela experiência de internação em uma UTI, referiram mudanças na visão que possuíam sobre o setor, compreendendo a sua finalidade. Observou-se que a terapia intensiva deixou de ser um ambiente gerador de medos e sinônimo de finitude, e tornou-se um lugar de renascimento, força e vida, e o suporte tecnológico é percebido como mecanismo para manutenção da vida.

Tem uma complexidade muito boa né, tecnologia avançada com máquinas novas, equipamento todo preparado "pra" dar suporte ao paciente em qualquer estado que ele esteja. (Turmalina)

Só depois que eu vivi lá, pra mim é completamente diferente, e falo para todo mundo, não tem explicação. [..] Hoje para mim é uma vida! A gente nasce de novo. (Topázio)

[..]A UTI tem médico 24horas, e aparelhos suficientes para ajudar qualquer pessoa, então tirou totalmente aquela impressão que eu tinha, de que UTI é só pra quem está morrendo. (Âmbar)

Esses aspectos foram bastante citados, os entrevistados perceberam a importância de todo cuidado intensivo para sua recuperação. $O$ fato de estarem com algum aparelho seja para verificação ou manutenção dos sinais vitais não gerou medo, ao contrário, contribuiu para alivio da ansiedade relacionado ao seu quadro clínico.

[..] Graças aquelas horas que fiquei com a VNI (ventilação não invasiva) no rosto que resolveu meu problema, se não tivesse resolvido teriam me intubado. (Esmeralda)

[.] Me dava era conforto, eu olhava minha pressão pelo vidro e eu via que estava normal, eu olhava meu batimento cardíaco e estava normal e aquilo me confortava, me dava aquele prazer. (Safira)

Outros aspectos, que corroboraram para a nova visão que os participantes tiveram sobre a unidade, após vivenciarem a internação, estão relacionados a competência e sensibilidade da equipe e a provisão dos materiais necessários para realização dos cuidados intensivos. Esses aspectos produziram sentimentos que geraram calma e segurança durante o período de internamento.

[..] A UTI é a chance que a gente tem de viver, porque toda equipe lá vai estar te esperando pra isso, por mais que você chegue lá em uma situação bem delicada, o objetivo deles é fazer de tudo por você. (Turquesa)

[..] Representa um salva vida, porque tem tudo, os aparelhos são bons, o pessoal sabe te conduzir, sabe falar com você, sabe te acalmar, não falta medicamento, não falta nada! Pra mim eu fiquei lá, e se pudesse voltar pra lá, eu voltaria. (Safira)

O acolhimento, as conversas, as brincadeiras na UTI e a resiliência da equipe frente a morte de outro paciente foram vistos como pontos positivos para adaptação e sentimento de segurança nos entrevistados.

[..] Eu gostei do barulho da equipe, porque eles são brincaIhões, o tempo todo alegre e em nenhum momento foram indiferentes, são muito prestativos [..] Quando acontece alguma coisa 
do paciente vir a óbito, eles se mantêm forte, não se abalam para demonstrar pra gente, porque ai você fica triste mas continua né, porque tem outros pacientes que precisam. (Turquesa)

Ressaltou-se ainda a visita de familiares e amigos na UTI, como fator que colaborou para que o processo de internação ocorresse de forma mais leve. $O$ contato com as pessoas que possuem afeto tranquiliza o paciente, que fica aguardando ansiosamente a chegada do horário da visita.

[..]Eu ficava contado as horas para chegar a hora de receber as visitas da minha filha, porque não somos daqui né, e aí a única visita que eu recebia além da de Jesus, era a da minha filha. (Topázio)

Nesse sentido, foi referido que o olhar sensível da equipe no intuito de valorizar este momento de visita e criar mecanismos para facilitar o encontro do paciente com seu familiar, produziram sentimentos de contentamento e contribuíram para aliviar o sofrimento, além de modificar o olhar do paciente sobre a unidade.

[..] os meninos me levavam lá pra fora, para o jardim lá na frente [..] eu encontrei minha família lá fora, porque meu netinho não pode entrar fiquei ali a tarde toda com minha mãe e meu neto. (Âmbar)

\section{Ambiente gerador de desconfortos e sofrimentos}

Apesar dos pacientes entrevistados relatarem mudanças na concepção sobre o setor de terapia intensiva, após passarem pelo internamento, alguns aspectos negativos foram relatados nessa segunda categoria. Por se tratar de um ambiente com inúmeros aparatos tecnológicos, o barulho dos aparelhos, a atemporalidade, e a temperatura do ambiente, foram as características negativas mais evidenciadas, pois são nocivos para o enfrentamento do adoecimento.

Alguns relatos referem a temperatura baixa do ambiente como algo desagradável, além da sensação de limitação por estarem conectados aos eletrodos e esfingmomanômetro.

[..] Pra mim eu achei que é muito frio, e meio desagradável, porque tem a sala tudo fechada, não pode nem respirar direito. (Opala)

[..] Agora, é a mesma coisa de estar preso, não pode sair para canto nenhum. É, tanto negócio que colocam em cima da gente, não pode nem mexer. (Jade)

Os barulhos dos equipamentos, das bombas de infusão, do colchão pneumático foram referidos como algo que prejudica o sono e repouso do paciente, tornando o ambiente desagradável e contribuindo para o estresse, preocupações e alterações do quadro clínico.

[..] $O$ que incomodava muito era o barulho daquele colchão, eu não conseguia dormir, era motorizado, essas noites que fiquei lá não dormi nada! [..] O barulho dos equipamentos também. (Jade)

A atemporalidade foi algo evidente que condicionava a desorientação no tempo e espaço. Os pacientes não conseguiam visualizar o ambiente externo e não havia relógio disponível, para que pudessem se situar no tempo.

[..] Ninguém sabia se era dia ou se era noite, com aquela lâmpada o tempo todo acesa, se apagasse não dava para ver nada [..] Eles deveriam deixar uma brecha de um vidro mais claro para o dia poder bater ali, e a gente ver que está sendo dia. (Turmalina)

Além disso, o fato de estar longe de casa, da família e ficar exposto sem roupas, foram fatores que influenciaram negativamente no enfrentamento e resiliência do paciente, propiciando tristeza, medos e preocupações.

[..]Teve momentos que eu senti tristeza, senti falta da minha filha, da família, de uma certa forma também eu fiquei isolada do mundo, não sabia nada que estava acontecendo lá fora. (Turquesa)

[..] A gente fica sozinho ali dentro, ainda de fralda e sem nenhum short porque não pode ficar com roupa. (Jade)

Saber que tem um paciente grave ao seu lado, ou até mesmo presenciar uma morte dentro da UTI, são fatores de tristezas e desarranjo emocional, pois todos os pacientes encontram-se em uma situação de passividade, gerando sentimento de impotência.

[..] o que mais me deixou triste, foi a moça que morreu e deixou o bebe dela, uma moça nova que se foi, perdeu a vida tão cedo, não vai poder nem criar o filho dela [..] as pessoas intubadas em minha frente, as vezes uns voltam e outros não voltam né, aquilo ali então, a gente fica um pouco assustado sabe. (Esmeralda)

\section{Mecanismos de enfrentamento para período de internação}

Frente aos sentimentos negativos de medo, preocupação e tristeza, os pacientes relataram como conseguiram enfrentar o processo de internação na UTI. No conjunto das falas, o exercício da espiritualidade se mostrou bastante evidente para construção da resiliência e reestabelecimento da saúde.

[..] Eu pedia Deus para me dá força e eu aguentar a vencer essa batalha, e aí ele me ajudou e eu estou aqui, graças a Deus. [..] Eu pedi força a Deus né, assim como o Senhor me ajudou a vencer a quimioterapia, o Senhor vai me ajudar vencer isso também, e venci. (Rubi)

Além disso, a espiritualidade proporcionou sentimentos de gratidão, após a alta e resolução do problema de saúde enfrentado, conforme pode ser visto nas falas:

[..] Agradecer vai ser em casa, eu vou rezar duas missas durante o período que eu estava aqui. Eu já sou fiel a Nossa Senhora Aparecida, e agora mais ainda. (Safira)

A fé foi referida como sendo capaz de operar milagres, e mesmo direcionando para uma força superior a responsabilidade principal para a sua recuperação, os entrevistados compreendiam a importância da equipe no seu processo de cura e assim clamavam por intervenção 
espiritual para a atuação dos profissionais da UTI. Além disso, demonstraram a necessidade de interceder pelos demais pacientes, pois os sofrimentos deles geravam sentimentos de solidariedade e compaixão.

[..] Eu falava, ó Senhor, abençoe todos que estão aqui, porque a gente depende primeiramente de Deus, e depois dos médicos, dos enfermeiros que estão aqui dentro para acompanhar a gente! [..] me senti segura na mão de Deus e nas mãos da equipe que estava me acompanhando. [..] Quem está na UTI está nas mãos de Deus. (Zircônia)

[..]Deus me deu aquela força, pareceu que estava em casa com a minha família [..] Tudo que você fazer na vida, tem que entregar na mão de Deus, porque só Ele que pode nos salvar. Se vai passar um rio e ele está cheio, se entregar na mão de Deus, você passa e não acontece nada, você vai pisando em cima da água, e Deus vai te levando. (Aquamarine)

\section{DISCUSSÃO}

Nesse estudo, constata-se que diversas são as representações e significados socialmente elaborados e compartilhados atribuídos a UTI, esses conhecimentos formados pelo senso comum, por vezes contribuem para o fortalecimento do temor relacionado ao ambiente e ao cuidado nele envolvido, associando-o a morte e sofrimento. Porém ao vivenciar internação nesta unidade, fatores negativos e positivos são experienciados, e a partir de estratégias de enfrentamento novos significados são atribuídos a UTI mudando as percepções pré-estabelecidas.

Um estudo realizado em um hospital geral no interior da Bahia, que objetivou relatar a percepção dos pacientes sobre a UTI, identificou o estigma social que esta unidade carrega, pelo fato de ser um local desconhecido e cercado de incertezas, os pacientes definiram-no principalmente como espaço de morte e sofrimento( ${ }^{(8)}$.

Essa visão sobre a UTI foi construída ao longo do tempo pela sociedade e pode ser explicada por meio da TRS. Essa teoria expressa uma forma de conhecimento socialmente elaborada e partilhada, carrega como significado a familiarização de ideias e valores dado ao que é desconhecido, para que possa ser aceito e justificado no meio social. É a partir das representações sociais que os indivíduos se comunicam e conseguem entender o ambiente que estão inseridos, se fundamenta nos conceitos formados através das relações interpessoais ${ }^{(9)}$.

Com relação às unidades de tratamento crítico percebe-se que os pacientes procuram ancorar ao aparato tecnológico aquilo que é ameaçador, como o medo em estar no ambiente de terapia intensiva, justificado pela atribuição do efeito terapêutico instituído(10).

As UTIs vivenciaram avanços consideráveis com objetivo de prestar uma assistência segura, eficiente e humanizada, através da aquisição de um suporte tecnológico cada vez mais especializado e a consequente necessidade de obtenção de recursos humanos mais qualificados. Entretanto, junto a tantos benefícios tecnológicos em favor da manutenção da vida, a UTI abrange um conjunto de estressores relacionados a terapêutica, influenciando negativamente no processo de internação(II).

A cascata de estressores gerados pela unidade são provenientes do ambiente e experiências desconhecidas que os pacientes estão propensos durante a internação. São inúmeros os ruídos produzidos por seus maquinários, devido a detecção de falha no funcionamento ou alterações orgânicas no paciente, como os presentes nos monitores multiparamétricos, bombas de infusão contínuas, ventiladores mecânicos, máquinas de hemodiálise, dentre outros. Sendo assim, um ambiente que outrora é responsável pela manutenção da vida, é também causador de estresse para os pacientes e seus familiares $^{(11-13)}$, como foi relatado também pelos participantes do presente estudo.

Além de todos esses fatores gerados pelo processo de hospitalização, o fato de estar internado em uma UTI gera uma carga deletéria adicional ao paciente e sua família. Isso pode ser observado em um estudo realizado em uma UTI de um hospital geral público de Recife-PE em 2014 , onde se evidenciou alguns estressores que influenciaram na recuperação dos pacientes internados, sendo eles: o barulho proveniente dos inúmeros equipamentos, distanciamento familiar, o medo da morte e o problema de saúde que levou à internação(11,14).

Corroborando com esses resultados, outros estudos trazem que durante o período de hospitalização o paciente é inserido em um cenário desconhecido, gerador de medos, ansiedades, isolamento social e tristeza ${ }^{(8,14)}$. A internação é acompanhada por um rompimento da vida anterior a hospitalização, ocasionado pelo distanciamento familiar, quebra de suas rotinas diárias e identidade ${ }^{(15)}$.

O distanciamento familiar associado a internação, confere uma ocorrência maior de medos e angustias, tornando primordial a presença da família no momento da hospitalização como facilitador no reestabelecimento do paciente que se encontra fragilizado e fora do convívio social(16). Diante disso, observa-se o contentamento e alegria durante os horários de visita, pois corresponde ao período no qual ocorre uma maior aproximação do convívio social.

Outro fator de desgastes para os pacientes na terapia intensiva é quando estes se encontram conscientes durante algum período da internação, pois isso permite a observação da gravidade de outros pacientes, os óbitos, além da rotina tecnicista, o que contribui para aumentar ainda mais o medo em relação ao ambiente e o seu prognóstico ${ }^{(17)}$.

Frente a isso, durante esse momento de adaptação a UTI, é fundamental que a equipe multidisciplinar seja facilitadora do processo de cuidar, promovendo momen- 
tos de diálogo e escuta qualificada a fim de minimizar os efeitos danosos do internamento, principalmente devido ao distanciamento familiar ${ }^{(8,11,18)}$.

A equipe multiprofissional deve se valer de métodos para que esse cuidado humanizado, integral e holístico se efetive, promovendo uma comunicação efetiva, respeito, apoio físico e emocional, e escuta das necessidades. Cada pessoa possui sua singularidade e estas devem ser consideradas por toda equipe de saúde, para o atendimento e promoção de uma atenção que contemple as esferas biopsicossocial e espiritual(15,19).

Nesse sentido, a equipe possui um papel de grande impacto para ancoragem do paciente com relação ao processo de internação na UTI, principalmente quando demonstram apreço e empatia durante a hospitalização. Estar aberto a quebra de paradigmas pelo bem-estar dos pacientes, realizar banhos de sol e momentos de passeio para os que se encontram acordados e estáveis, proporcionar encontros com os familiares, são medidas que trazem inúmeros benefícios que refletem em satisfação e possíveis melhorias no quadro clínico.

O processo de ancoragem utilizado pelos pacientes desse estudo é visivelmente evidenciado, como explicado pela TRS, em que buscou-se tornar familiar o desconhecido através de mecanismos de enfrentamento. A TRS explica essa dinâmica através da objetivação e da ancoragem, sendo a objetivação o método de tornar subjetivo em algo objetivo, de forma que as imagens se transformam em componentes da realidade; e a ancoragem como as significações existentes no grupo social representando o objeto ${ }^{(20)}$. Dessa forma, a objetivação corresponde à realidade criada pelos pacientes a respeito da UTI, e a ancoragem os significados atribuídos para tornar familiar esse ambiente desconhecido.

Diante disso, a espiritualidade significa para o paciente o conforto e salvação da vida, dando suporte e amparo, designando-se como estratégia para superação das adversidades. Além disso, o processo da espiritualidade, é um mecanismo que associado a humanização da equipe, contribui para melhores resultados à experiência de internação(14-15).

Portanto, evidencia-se que o processo de ancoragem foi determinante para mudança da percepção acerca da UTI, auxiliando os pacientes na recodificação de suas representações sobre o ambiente, se valendo das características positivas como a empatia e o cuidado humanístico dos profissionais, além dos mecanismos de espiritualidade para o enfrentamento.

\section{CONCLUSÃO}

A pesquisa constatou a mudança de percepção associada a UTI, embora tenha evidenciado vários aspectos negativos, os pacientes demonstraram situações que influenciaram positivamente, sendo determinantes para modificação da concepção. Os pacientes ancoram esta mudança no suporte tecnológico, no cuidado humanizado da equipe, na fé e na espiritualidade, sendo estes mecanismos de enfrentamento que tornaram possíveis a familiarização do desconhecido que era UTI.

A percepção do ambiente da UTI anterior a internação foi pautada nas definições do senso comum, baseadas em imagens criadas em detrimento do ouvir falar, e até mesmo de experiências de outrem sobre a internação, a transformando em um espaço gerador de medo, morte, tristeza e sofrimento biopsicossocial. Contudo, após os pacientes pesquisados vivenciarem a internação, mudanças positivas ocorreram nas representações que possuíam da UTI, associando-a agora a um local seguro, de recuperação e de reestabelecimento da saúde, formada por uma equipe acolhedora e empática.

Entretanto, constatou-se que 0 isolamento familiar corresponde a um dos maiores aspectos negativos geradores de tristeza e medo, exigindo maior resiliência para o paciente que se encontra fragilizado, caracterizando a UTI como causador de desconfortos devido rompimento do convívio coletivo e das atividades de vida diária.

Diante disso, esse estudo contribui também, para identificar e discutir as representações sociais da UTI e sua influência no processo de hospitalização e enfrentamento do adoecimento, uma vez que possui papel dominante nas definições socialmente elaboradas. Neste caso, a experiência positiva no internamento, ofereceu suporte e subsídio no processo de objetivação e ancoragem, associado ao cuidado singular e humanizado da equipe multiprofissional, o que tornou o ambiente menos ameaçador. Torna-se, portanto, fundamental a formação de novas representações sociais, que se associem não somente aos aspectos negativos, mas aos benefícios e finalidades da UTI.

Este estudo apresenta como limitações ter um número reduzido da amostra e demonstrar uma realidade local e de um único hospital da rede pública. Assim, os resultados obtidos não são uma representação definitiva sobre a representação das vivências de paciente em UTI, sendo necessários outros estudos, com amostra maior, para elucidação da temática.

No entanto, considera-se que os resultados desse estudo têm importância na medida em que contribuiu com o acervo científico, fomentando discussões sobre a importância do cuidado, holístico, humanizado e comprometido pela equipe multiprofissional, ao paciente internado em UTI. Confluindo em um cuidado pautado em uma postura empática e centrado nas necessidades do indivíduo, não somente no aspecto físico, mas também emocional e espiritual. 


\section{REFERÊNCIAS}

I. Galindo IS, Kempfer SS. Formação do enfermeiro para atuação no cuidado a pessoas em terapia intensiva. In:Vargas MAO, Nascimento E. PROENF Programa de Atualização em Enfermagem: Terapia Intensiva: Ciclo I. Porto Alegre: Artmed Panamericana, vol. 2; 2017. p. 9-28.

2. Eugênio CS, Filho MCB, Souza EM. Visita aberta em UTI adulto: Utopia ou realidade? Revista Enfermagem UFSM [Internet]. 2017 [acesso em 18 out 2018]; 7(3):539-549. Disponível em: https://periodicos.ufsm.br/reufsm/article/ view/22692/pdf

3. Eulálio MC, Júnior EGS, Souto RQ, Brasileiro LEE. Unidade de terapia intensiva: significados para pacientes em tratamento. Revista Ciência e Saúde [Internet]. 2016 [acesso em 16 out 2018]; 9(3): 182- I89. Disponível em: http://revistaseletronicas.pucrs.br/ojs/index.php/faenfi/article/view/23990

4. da Silva Schran Didomênico L, Rodrigues da Silva CarvaIho A, Martins L, Augusto Lordani T, Campos de Oliveira J, Cadore Weis Maia M. Espiritualidade no cuidado em saúde e enfermagem: Revisão integrativa da literatura. Revista Enfermagem Atual [Internet]. 26set.2019 [acesso I2mar.2020];89(27). Disponível em: https://revistaenfermagematual.com.br/index.php/revista/article/view/456

5. Jodelet D. Experiência e representações sociais. In: Menin MSS, Shimizu AM. Experiência e representação social: questões teóricas e metodológicas. São Paulo: Casa do Psicólogo; 2005. p. 23-56.

6. Bardin L.Análise de conteúdo.70a. ed. São Paulo; 20 I I. p 229.

7. Ministério da Saúde (BR). Conselho Nacional de Saúde. Diretrizes e normas regulamentadoras de pesquisas envolvendo seres humanos. Resolução $n^{\circ}$ 466. [Internet]. 2012 [acesso em 19 out 2018]. Brasília: Ministério da Saúde. Disponível em: http://bvsms.saude.gov.br/bvs/saudelegis/ cns/2013/res0466_12_12_20I2.html

8. Nunes ECDA, Lima SFI, Reis SO, Teixeira PB. O outro lado da terapia intensiva - percepções no pós alta. Revista de Enfermagem UFPE [Internet]. 2017[acesso em 19 out 2018]; I I(I2):5252-5258. Disponível em: https://periodicos.ufpe.br/revistas/revistaenfermagem/article/download/226/5/25470

9. Jodelet, D. Loucura e Representações Sociais, Petrópolis, RJ:Vozes; 20I5. p.33-58.

10. Moscovici S. O fenômeno das representações sociais. In: Representações sociais: investigações em psicologia social. 2a.ed. Petrópolis, RJ:Vozes; 2003. cap. I, p. 29-109.

I I. Andrade RZ, Resende MC.Avaliação dos agentes estressores e da resiliência em pacientes internados na unidade de terapia intensiva. Revista Perspectivas em Psicologia [Internet]. 2014 [acesso 19 out 2018]; I8(I): 194-2I3.Disponível em: http://www.seer.ufu.br/index.php/perspectivasempsicologia/article/view/29352.

I2. Guerrer FJL, Bianchi ERF. Estressores em UTI. In: Padilha
KG,Vattimo MFF, Silva SC, Kimura M. Enfermagem em UTI: cuidando do paciente crítico. I' .ed. São Paulo:Manole; 2010, cap. 58, p. I367-1378.

13. Freitas KO, Torres RSC, Silva SED, Monteiro GO,Vascocelos EV. Representações Sociais de Familiares de Pacientes em Unidades de Terapia Intensiva: Implicações no Cuidado de Si. Rev Fund Care Online [Internet].2019. abr./jun.; [acesso I2 mar 2020]; I I(3):664-67I. Disponível em: http://dx.doi. org/ I0.9789/2 I75-536I.2019.v I Ii3.664-67|

14. Abrão FMS, Santos EF, Araújo RA, Oliveira RC, Costa AM. Sentimentos do paciente durante a permanência em unidade de terapia intensiva. Revista Enfermagem UFPE [Internet]. 2014 [acesso em 16 out 2018];8(3):523-29. Disponível em: https://periodicos.ufpe.br/revistas/revistaenfermagem/ article/download/9706/9776.

15. Camponogara SC, Viero CM, Pinno C, Soares SGA, Rodrigues IL, Cielo C. Percepções de pacientes pós-alta da unidade de cuidados intensivos sobre a hospitalização nesse setor. Revista Enfermagem do Centro-Oeste [Internet]. 2015 [acesso em 20 out 2018]; 5(I):I505-I5I3. Disponível em: http://www.seer.ufsj.edu.br/index.php/recom/ article/view/747

16. Leite MT, Schons VF, Silva LAA, Muller LA, Pinno C, Hildebrandt LM. Hospitalização em Unidade de Terapia Intensiva na voz de idosos e familiares. Revista Estudos interdisciplinares sobre o envelhecimento [Internet]. 2015 [acesso em 17 out 2019]; 20(2):535-549. Disponível em: https://seer. ufrgs.br/RevEnvelhecer/article/view/46060

17. Nogueira JJQ, Ferreira JÁ,Albuquerque AM,Agra G. Fatores agravantes e atenuantes à percepção de morte em UTI: a visão dos pacientes. Revista online de Pesquisa Cuidado é Fundamental [Internet]. 2017 [acesso em 03 nov 2018]; 9(I):5I-56. Disponível em: http://www.seer.unirio.br/index. php/cuidadofundamental/article/view/4255

18. Vasconelos EV, Freitas KO, Silva SED, Baia RSM, Tavares RS, Araújo JS. O cotidiano de familiares de pacientes internados na uti: um estudo com as representações sociais. Revista de Pesquisa Cuidado é Fundamental [Internet]. 2016 [acesso em I6 out 2018]; 8(2):4313-4327. Disponível em: http://www.seer.unirio.br/index.php/cuidadofundamental/ article/view/4366

19. Luiz FF, Caregnato RCA, Costa MR. Humanization in the Intensive Care: perception of family and healthcare professionals. Revista brasileira de enfermagem [Internet]. 2017 [acesso em 19 out 2018]; 70(5):1040-1047. Disponível em: http://www.scielo.br/scielo.php?script=sci_arttext\&pi$d=S 0034-7|6720| 7000501040$

20. Moscovici, S.A psicanálise: sua imagem e seu público. Petrópolis:Vozes, 2012

Recebido: 2019-10-17

Aceito: 2020-0I-15 